\title{
Reduced Enterobacterial and Increased Staphylococcal Colonization of the Infantile Bowel: An Effect of Hygienic Lifestyle?
}

\author{
INGEGERD ADLERBERTH, ERIKA LINDBERG, NILS ÅBERG, BILL HESSELMAR, ROBERT SAALMAN, \\ INGA-LISA STRANNEGÅRD, AND AGNES E. WOLD
}

\author{
Department of Clinical Bacteriology [I.A., E.L., A.E.W.], Göteborg University, S-413 46 Göteborg, Sweden; Department of Biomedical \\ Laboratory Science [E.L.], Göteborg University, S-405 30 Göteborg, Sweden, Department of Pediatrics [N.A., B.H., R.S., I.-L.S.], \\ Göteborg University, Queen Silvia Childrens Hospital, S-416 85 Göteborg, Sweden
}

\begin{abstract}
The modern Western lifestyle may have altered the composition of the commensal microflora. Here, we investigated the first year's intestinal colonization pattern in 99 vaginally delivered Swedish infants and 17 delivered by cesarean section. Rectal swabs obtained at $3 \mathrm{~d}$ of age were cultured for aerobic bacteria and fecal samples obtained at 1,2, 4, and $8 \mathrm{wk}$ and at 6 and 12 mo of age were cultivated quantitatively for aerobic and anaerobic bacteria. Vaginally delivered infants more often had Escherichia coli compared with cesarean section-delivered infants, whereas the latter more frequently carried other enterobacteria, such as Klebsiella and Enterobacter. Independent of delivery mode, it took 2 mo until most infants were colonized by enterobacteria, traditionally the first colonizers. In contrast, coagulase-negative staphylococci colonized $99 \%$ of the infants from d 3 onwards. The poor adaptation of staphylococci to the gut was shown by declining population sizes after some weeks. Dominating anaerobes were initially bifidobacteria and clostridia, whereas Bacteroides initially colonized only $30 \%$ of vaginally delivered infants and increased very slowly in prevalence. Bacteroides colonization was delayed up to $1 \mathrm{y}$ in cesarean section-delivered compared with vaginally delivered infants. Our results show that some "traditional" fecal bacteria are acquired late today especially in cesarean section-delivered infants, probably due to limited environmental circulation. In their absence, skin bacteria like staphylococci have become the first gut colonizers. (Pediatr Res 59: 96-101, 2006)
\end{abstract}

B acteria establish in the intestinal tract immediately after delivery. Escherichia coli and enterococci are present in infant stools within a few days $(1,2)$ and anaerobic bacteria of the Bifidobacterium, Clostridium, and Bacteroides genera within a week $(1,2)$. Other anaerobes are successively established, resulting in a highly diverse microflora at some years of age (3).

The mother's vaginal, fecal, and perineal microbial communities are common sources of infantile bacterial colonization. Infants delivered by cesarean section, who are not ex-

Received March 15, 2005; accepted June 15, 2005

Correspondence: Ingegerd Adlerberth, M.D., Department of Clinical Bacteriology, Göteborg University, Guldhedsgatan 10, S-413 46 Göteborg, Sweden; e-mail: ia@microbio.gu.se

This study was supported by grants from the European Commission (QLK-200000538), the Swedish Foundation for Health Care Sciences and Allergy Research, the Asthma and Allergy Foundation, the Cancer and Allergy Foundation, the Swedish Free Masonry Foundation, and the Swedish Medical Research Council.

DOI: 10.1203/01.pdr.0000191137.12774.b2 posed to such bacteria, are slower to acquire, e.g. Bacteroides and bifidobacteria $(4,5)$. However, environmental sources may contribute significantly to the baby's intestinal colonization $(6,7)$. Thus, infants in developing countries are colonized earlier and by a greater variety of intestinal bacteria than infants in industrialized countries $(8,9)$. Cesarean sectiondelivered infants in Pakistan acquire E. coli almost as early as vaginally delivered ones (8). These findings point to the abundance of faecal bacteria in such environments.

The microflora is a major stimulus for the developing immune system (10), and promotes tolerance to innocuous antigens (11). An altered intestinal microflora may therefore underlie the increased incidence of allergies (12). The present study was initiated to characterize intestinal colonization in a cohort of Swedish infants with high risk of developing allergy, and to determine whether the colonization pattern has changed in the last decades. One hundred sixteen infants were followed with regular sampling and quantitative culture of the intestinal microflora. Colonization by E. coli (13) and Staphylococcus aureus (14) in part of the cohort and colonization by lactobacilli in the entire cohort (15) has been reported elsewhere. The colonization pattern was related to delivery mode and compared with earlier studies of the intestinal colonization pattern of Western infants.

\section{MATERIALS AND METHODS}

Infants, delivery, and hospital care. Swedish infants $(n=116)$ born in 1998-2000 at the Sahlgrenska University Hospital were studied, 99 of whom were delivered vaginally and 17 by cesarean section. They participated in a prospective birth-cohort study, ALLERGYFLORA, investigating the relation between intestinal colonization pattern and allergy development. Informed consent was obtained and the Ethics Committee of Göteborg University approved the study.

Concerning perinatal hygiene, genital wash with chlorhexidine was done before vaginal examinations, which were performed initially and every sixth 
hour during labor. In addition, some mothers took a shower with chlorhexidine soap on arrival in the delivery ward.

The average hospital stay was $2.6 \mathrm{~d}$ for vaginally delivered and $4.9 \mathrm{~d}$ for cesarean section-delivered infants. Eight infants stayed on average $2.2 \mathrm{~d}$ at the neonatal ward before transfer to the maternity ward. Rooming in was practiced at the maternity ward, and the infants were almost exclusively handled by the parents and spent the night with their mothers. The maternity and neonatal unit staff practiced regular hand washing and alcohol disinfection.

Six mothers, three of whom underwent cesarean section, received antibiotics in relation to delivery: penicillin $\mathrm{G}(n=1)$, cefuroxime $(n=1)$, cefuroxime + metronidazole $(n=3)$, in one case followed by cefadroxil, unknown $(n=1)$.

Most parents were urban professionals living in high-standard houses or apartments, and $89 \%$ of the infants had (an) allergic parent(s). Disinfectants are not used regularly in Swedish households. Regular soap and water is most common for personal hygiene, but disposable sanitary towels moistened with disinfectants are often used for cleaning infants, particularly outside the home.

All mothers commenced breast-feeding, but six stopped before 2 mo and thereafter gave commercial formula. Seventy percent of the infants were fully breast-fed for at least 4 mo and $74 \%$ were partially breast-fed $>6$ mo.

Thirty infants $(26 \%)$ received antibiotics in their first year, $7 \%(n=8)$ more than one type: penicillin $(n=21)$, ampicillin/amoxicillin $(n=13)$, trimethoprim/sulphamethoxazole $(n=4)$, erythromycin $(n=3)$, flucloxacillin $(n=1)$, cefuroxime $(n=1)$, ceftibuten $(n=1)$, tobramycin $(n=1)$, and nitrofurantoin $(n=1)$. Eight of the vaginally delivered $(8 \%)$ and two of the cesarean section-delivered infants $(12 \%)$ received antibiotics during the first half year, and $22(22 \%)$ and $1(6 \%)$, respectively, during the second half year.

Sampling and culture of the intestinal microflora. The rectal flora was sampled $3 \mathrm{~d}$ after delivery using a cotton-tipped swab. The swab was transported to the laboratory in COPAN's transportation medium, and cultured for facultative bacteria within $24 \mathrm{~h}$.

Fecal samples were obtained at 1,2, 4, and $8 \mathrm{wk}$ and at 6 and 12 mo of age and cultured quantitatively for facultative and anaerobic bacteria. Freshly voided feces were collected by the parents and placed in a sterile Petri dish in a plastic bag with anaerobic atmosphere (AnaeroGen Compact, Oxoid Ltd, Basingstoke, UK), which was kept refrigerated until transported to the laboratory. Using this procedure, counts of relevant bacterial groups were unaltered compared with immediate culture (data not shown). A calibrated spoon of feces was serially diluted in sterile peptone water. Appropriate dilutions were plated on selective and nonselective media (Table 1). From each growth medium, free-lying colonies of different morphology were separately enumerated, Gram-stained, examined in the microscope, and subcultured for purity. The limit of detection was $330\left(10^{2.52}\right)$ CFU (colony forming units)/g of feces.

Table 1. Culture media an conditions of incubation

\begin{tabular}{|c|c|c|c|c|}
\hline Medium & $\begin{array}{l}\text { Time } \\
\text { (d) }\end{array}$ & $\begin{array}{l}\text { Culture } \\
\text { conditions }\end{array}$ & $\begin{array}{c}\text { Bacteria } \\
\text { atmosphere }\end{array}$ & Reference \\
\hline Colombia blood & 1 & Aerobic & Total aerobes & \\
\hline Drigalski & 1 & Aerobic & Enterobacteriaceae & (35) \\
\hline Staphylococcus agar & 2 & Aerobic & Staphylococcus spp. & (36) \\
\hline Enterococcosel agar & 1 & Aerobic & Enterococcus spp. & (37) \\
\hline \multirow{2}{*}{ Brucella blood } & 3 & Anaerobic $^{\dagger}$ & Total anaerobes & \\
\hline & 3 & Anaerobic & $\begin{array}{l}\text { Spore formers } \\
\quad(\text { Clostridium })^{\S}\end{array}$ & \\
\hline BBE agar* & 3 & Anaerobic & $\begin{array}{l}\text { Bacteroides fragilis } \\
\text { group }\end{array}$ & (38) \\
\hline Beerens agar & 3 & Anaerobic & Bifidobacterium spp. & (39) \\
\hline $\mathrm{CCFA}^{* *}$ & 3 & Anaerobic & C. difficile & (40) \\
\hline
\end{tabular}

Rectal swabs and serially diluted fecal samples were cultivated at $37^{\circ} \mathrm{C}$ on the above-specified media for enumeration of the bacterial groups indicated in the table.

* Bacteroides bile esculin agar.

** Cycloserine cefoxitin fructose egg yolk agar.

$\dagger$ Cultured in jars using the BBL GasPak anaerobic system (Becton Dickinson Microbiology Systems, Sparks, NV), using agar plates prereduced for $24 \mathrm{~h}$.

$\ddagger$ Isolates growing aerobically were not included in the counts.

$\S$ For spore formers (clostridia), feces diluted 1:10 was mixed 1:1 with 99\% ethanol and incubated on a shaker at room temperature for $30 \mathrm{~min}$ to kill vegetative cells, where after the sample was diluted and plated.
Anaerobes were also subcultured under aerobic conditions (Colombia blood agar plates, $24 \mathrm{~h}$ at $37^{\circ} \mathrm{C}$ ), and isolates showing aerobic growth were discarded. However, scanty aerobic growth was accepted for anaerobic Gram-positive rods.

Bacterial identification. The bacterial groups quantified on each plate are shown in Table 1. Enterobacteria were speciated using API20E biotyping (API Systems SA, La Balme les Grottes, Montalieu-Vercieu, France). Staphylococci were identified by Gram-stained appearance and positive catalase reaction. Staphylococci positive in the coagulase test were defined as $S$. aureus, the others as coagulase-negative. Enterococci were identified by esculin hydrolysis and typical Gram-stained appearance.

Bacteroides were speciated by Rapid ID 32A (API Systems). Clostridia, defined as straight Gram-positive or Gram-labile rods with or without spores isolated from alcohol-treated samples cultivated on Brucella blood agar, were speciated using Rapid ID32A. Clostridium difficile were quantified on selective medium (Table 1) and speciated using Rapid ID32A. Bifidobacteria were identified using a genus-specific PCR (16).

Statistics. Frequencies were compared using Fisher's exact test. Bacterial population counts were compared using Wilcoxon signed-rank test.

\section{RESULTS}

Prevalence of facultative bacteria and its relation to delivery mode. It took 2 mo before $>90 \%$ of the infants had enterobacteria (e.g. E. coli, Klebsiella, or Enterobacter) in their stools. In contrast, all infants harbored staphylococci (coagulase-negative staphylococci and/or S. aureus) from $3 \mathrm{~d}$ of age. Enterococci also appeared earlier than enterobacteria (Fig. 1).

The effect of delivery mode is shown in Figure 2. Coagulase-negative staphylococci and enterococci colonized vaginally and cesarean section-delivered infants equally early (Fig. 2, $a$ and $b$ ). In contrast, cesarean section-delivered infants less often harbored $E$. coli than vaginally delivered infants over the first 6 mo (Fig. $2 c)(3 \mathrm{~d}, p=0.01 ; 1 \mathrm{wk}, p=$ $0.001 ; 2 \mathrm{wk}, p=0.009 ; 4 \mathrm{wk}, p=0.06 ; 2 \mathrm{mo}, p=0.12 ; 6$ mo, $p=0.03$ ).

Enterobacteria other than E. coli (mostly Klebsiella and Enterobacter spp.) were isolated less often from vaginally delivered than from cesarean section-delivered infants $(3 \mathrm{~d}, p$ $=0.07 ; 1 \mathrm{wk}, p=0.04 ; 2 \mathrm{wk}, p=0.02$ ) (Fig. $2 d$ ).

Population levels of facultative bacteria. Facultative bacteria colonized at high levels during the first 6 mo but decreased moderately thereafter $\left(6 \mathrm{mo}, 10^{9.0} ; 12 \mathrm{mo}, 10^{8.3}\right.$

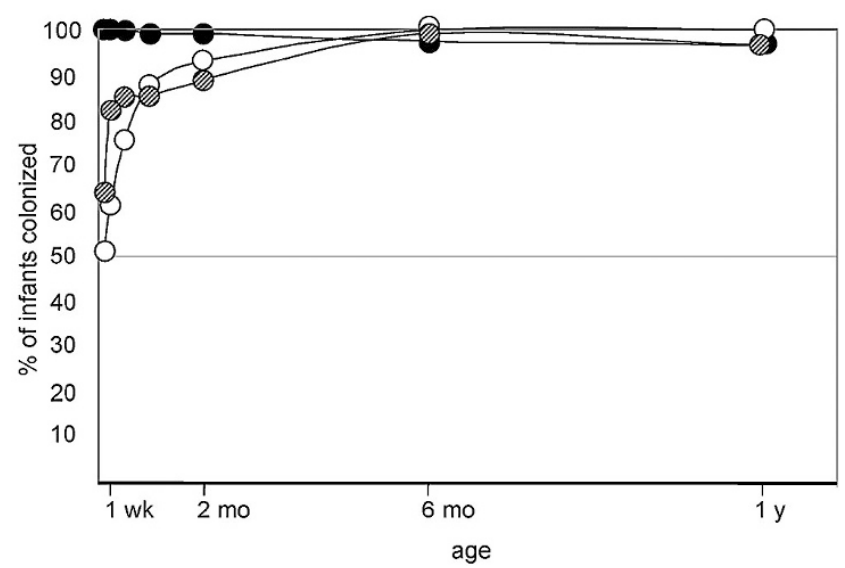

Figure 1. Frequency of colonization by major groups of facultative bacteria in Swedish infants. Enterobacteria (open symbols), staphylococci (filled symbols), and enterococci (hatched symbols) were identified in fecal samples obtained from 116 Swedish infants at different time-points during the first year of life. 

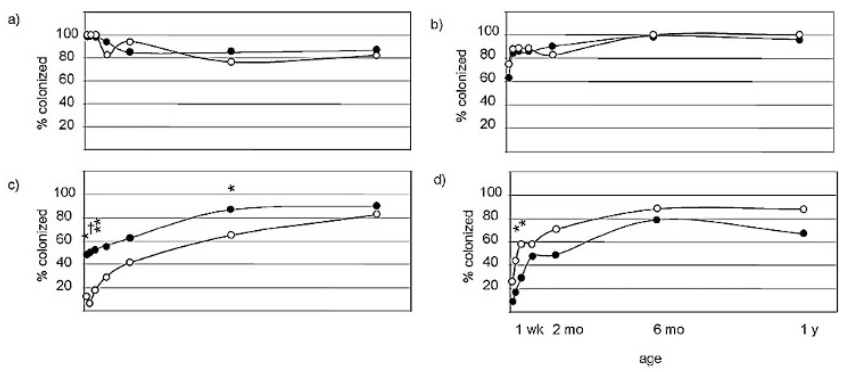

Figure 2. Intestinal colonization by facultative bacteria in relation to delivery mode. Colonization of vaginally (filled symbols) and cesarean sectiondelivered (open symbols) infants by $(a)$ coagulase-negative staphylococci, $(b)$ enterococci, (c) E. coli, and (d) other enterobacteria at different time-points during the first year of life. Asterisks indicate significant differences between vaginally and cesarean section-delivered infants $(* p<0.05$, $* * p<0.01$, $* * * p<0.001)$.

CFU/g feces, $p<0.0001$ ). The levels differed little between vaginally and cesarean section-delivered infants, provided they were colonized by the bacteria in question. However, cesarean section-delivered infants colonized by enterobacteria other than E. coli had higher counts of these bacteria than vaginally delivered infants by 6 mo of age $\left(10^{8.6}\right.$ versus $10^{7.7}$ CFU/g feces, $p=0.0006$ ).

Figure 3 shows the fecal counts of different facultative bacteria in colonized infants, vaginally and cesarean sectiondelivered infants combined. E. coli were $0.5-1 \log$ unit more numerous than other enterobacteria and enterococci throughout the first year. The counts of all three groups decreased significantly after 6 mo of age ( $p<0.0001$ for each comparison) (Fig. 3).

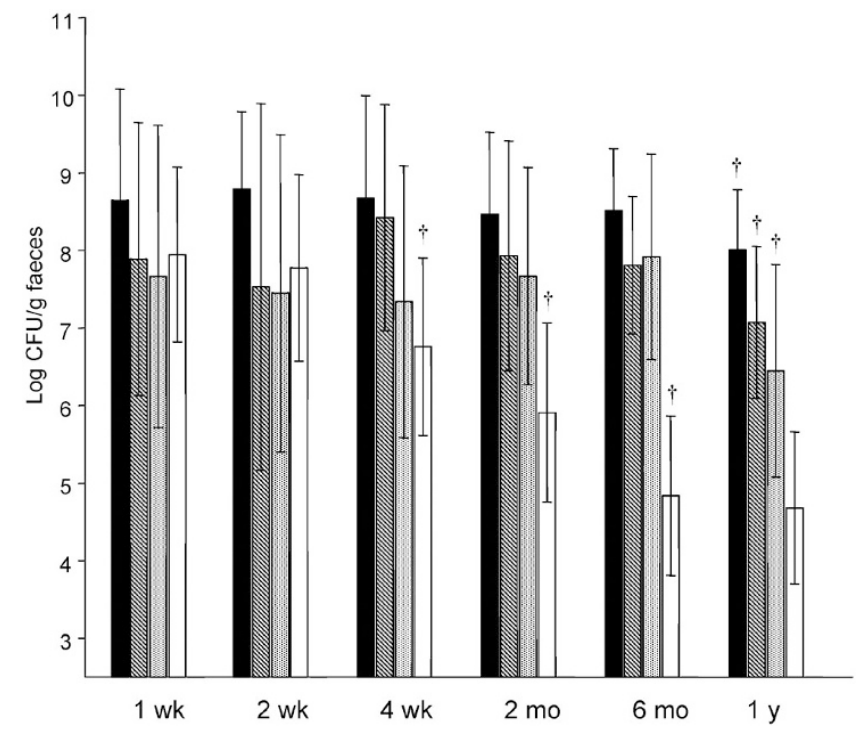

Figure 3. Population levels of different facultative bacteria in culturepositive infants. Population levels (log CFU/g feces) of E. coli (filled bars), other enterobacteria (hatched bars), enterococci (dotted bars), and coagulasenegative staphylococci (open bars) in culture-positive infants at different time-points after birth. Both vaginally and cesarean section-delivered infants are included. Mean population levels (bars) and standard deviations are presented. Asterisks above the bars indicate significantly decreased counts compared with the previous sampling occasion $\left({ }^{\dagger} p<0.001\right)$.
Coagulase-negative staphylococci were initially quite numerous but decreased significantly compared with the previous sample from 4 wk until 6 mo of age $(p<0.0001$ for all comparisons).

Prevalence of anaerobic bacteria and its relation to delivery mode. Anaerobic bacteria were recovered from the feces of 112/116 infants by $1 \mathrm{wk}$ of age. Bifidobacteria dominated initially. Clostridia caught up at $6 \mathrm{mo}$, whereas Bacteroides initially colonized $<1 / 3$ and increased only slowly in prevalence after 2 mo (Fig. 4).

The effect of delivery mode on anaerobic colonization is shown in Figure 5. Bifidobacteria were more common in vaginally delivered than cesarean section-delivered infants 1 wk after delivery (69\% versus $44 \%, p=0.08$ ) (Fig. $5 a$ ). Clostridia were instead significantly more common among cesarean section-delivered infants ( $1 \mathrm{wk}, p=0.01 ; 2 \mathrm{wk}, p=$ 0.003) (Fig. 5b).

Colonization by $C$. difficile increased steadily over the first year (Fig. 5c). Although cesarean section-delivered infants were consistently more often colonized by $C$. difficile, the difference was nonsignificant at all time-points (12 mo, $p=$ $0.11)$.

Bacteroides spp. were found in approximately $30 \%$ of the vaginally delivered infants in the first $2 \mathrm{mo}, 43 \%$ at $6 \mathrm{mo}$, and $75 \%$ at 1 y of age (Fig. $5 d$ ). Bacteroides first appeared in cesarean section-delivered infants at 2 mo of age, when 1/17 was colonized (Fig. $5 d$ ). Bacteroides spp. were less frequent in cesarean section-delivered than vaginally delivered infants during the first year of life ( $1 \mathrm{wk}, p=0.01 ; 2 \mathrm{wk}, p=0.003$; $4 \mathrm{wk}, p=0.006 ; 2 \mathrm{mo}, p=0.07 ; 12 \mathrm{mo}, p=0.08$ ).

Population levels of anaerobic bacteria. Anaerobic population counts increased from $10^{10.1}$ to $10^{10.3} \mathrm{CFU} / \mathrm{g}$ between 1 wk and $1 \mathrm{y}$ of age ( $p=0.01$, only colonized infants included). The levels were equal in vaginally and cesarean sectiondelivered infants.

When present, bifidobacteria and Bacteroides were most numerous (Fig. 6). Clostridial spores amounted to $10^{5}-10^{6}$ $\mathrm{CFU} / \mathrm{g}$ feces. Vegetative clostridial bacterial levels could not be determined due to lack of selective media. However,

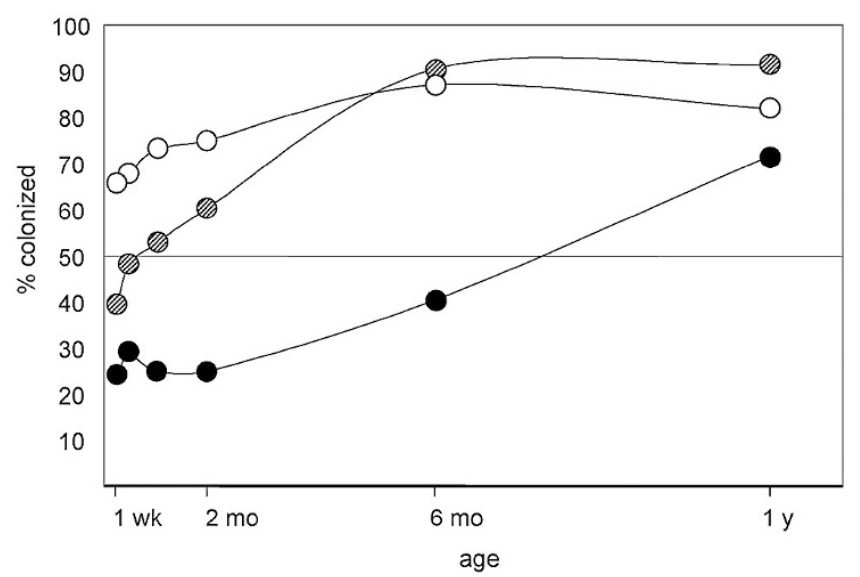

Figure 4. Frequency of colonization by major groups of anaerobic bacteria in Swedish infants. Bifidobacteria (open symbols), clostridia (hatched symbols), and Bacteroides spp. (filled symbols) were identified in fecal samples obtained from 116 Swedish infants at different time-points during the first year of life. 

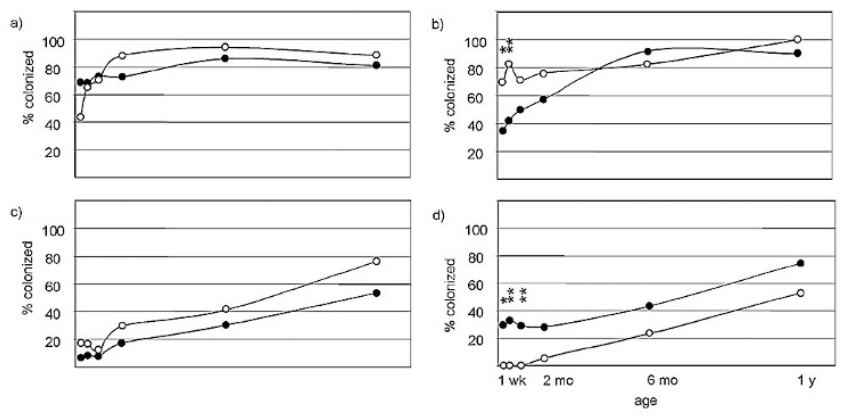

Figure 5. Intestinal colonization by anaerobic bacteria in relation to delivery mode. Colonization of vaginally (filled symbols) and cesarean sectiondelivered infants (open symbols) by (a) bifidobacteria, $(b)$ clostridia, $(c) C$. difficile, and $(d)$ Bacteroides at different time-points during the first year of life. Asterisks indicate significant differences between vaginally and cesarean section-delivered infants $(* p<0.05, * * p<0.01)$.

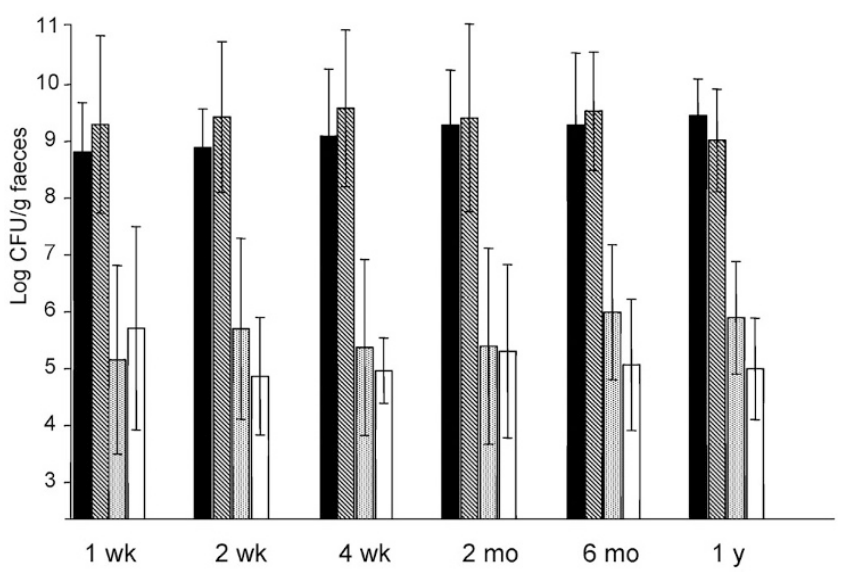

Figure 6. Population levels of different anaerobic bacteria in culture-positive infants. Population levels (log CFU/g feces) of Bacteroides (filled bars), bifidobacteria (hatched bars), spore-forming clostridia (dotted bars), and $C$. difficile (open bars) in culture-positive infants at different time-points after birth. Both vaginally and cesarean section-delivered infants are included. Mean population levels (bars) and standard deviations are presented.

clostridia often grew in high counts $\left(10^{8}-10^{10} \mathrm{CFU} / \mathrm{g}\right.$ feces $)$ on the nonselective Brucella blood agar plate.

Influence of allergic heredity on intestinal colonization pattern. The cohort was selected to have high risk of developing allergies and most infants had (an) allergic parent(s). Thirteen infants had no allergy in the family. Their colonization pattern did not differ from the majority, except that they were significantly less often colonized with clostridia at $1 \mathrm{y}$ of age $(p=0.014)$.

Influence of antibiotics on intestinal colonization pattern. Colonization in the first 6 mo was compared between infants receiving, or not receiving antibiotics during this period. Colonization at 12 mo was compared between infants receiving, or not receiving antibiotics between 6 and 12 mo of age.

Antibiotic treated infants less often had clostridia than nontreated infants ( $1 \mathrm{wk}, p<0.10 ; 2 \mathrm{wk}, p<0.05 ; 1 \mathrm{mo}, p$ $=0.19 ; 6 \mathrm{mo}, p<0.01 ; 12 \mathrm{mo}, p=0.11)$. Instead, during the first 2 mo of life, they tended to more often have E. coli ( 3 d, $1 \mathrm{mo}, p<0.10 ; 2 \mathrm{mo}, p<0.05)$ and $S$. aureus ( $3 \mathrm{~d}, p=0.15$; 1 wk, $p=0.11 ; 2$ wk, $p<0.10$; 2 mo $p=0.17)$ than nontreated infants.
Infants to mothers treated with antibiotics around delivery less often had $E$. coli than other infants $(3 \mathrm{~d}, 1,2$ and $4 \mathrm{wk}, p$ $<0.05 ; 2 \mathrm{mo}, p<0.01 ; 6 \mathrm{mo}, p=0.05)$. They also tended to less often have bifidobacteria $(1 \mathrm{mo}, p<0.05)$ and clostridia $(2 \mathrm{mo}, p<0.05 ; 6 \mathrm{mo}, p<0.10)$.

\section{DISCUSSION}

We here describe the longitudinal intestinal colonization pattern during the first year of life in more than 100 infants born in Sweden by the end of the 20th century. To our knowledge, this is the largest birth cohort studied with respect to the establishment of the commensal intestinal microflora. Although differences in methodology make direct comparisons with studies from the 1970s and 1980s difficult, there are indications that infantile colonization might have changed in the last decades in Sweden.

A striking observation was the ubiquitous colonization by coagulase-negative staphylococci throughout the first year of life. These bacteria, not previously regarded as intestinal commensals, initially reached as high population counts as typical fecal bacteria like Klebsiella, Enterobacter, and enterococci. S. aureus was isolated from three out of four infants in this birth cohort, as previously reported (14). Staphylococci were infrequent in the bowel flora of Western infants investigated in the 1970s $(2,17,18)$. In the 1980s, S. epidermidis were isolated from 30 to $70 \%$ of 1-wk-old Swedish infants $(9,19,20)$, suggesting that they had become more common. Anecdotally, increased staphylococcal colonization between 1975 and 1995 was described in France (21).

Staphylococci are more common in breast-fed than bottlefed infants $(20,22)$. The high prevalence of staphylococci might relate to the very high breast-feeding rate. However, the few bottle-fed infants were equally often colonized by $S$. aureus as the breastfed majority (Lindberg et al., manuscript in preparation). We suggest that lack of competition from "professional" gut bacteria may explain the expansion of staphylococci in the infantile gut flora. "Classical" fecal bacteria like E. coli appeared late in the present cohort (13). Only $56 \%$ of vaginally delivered infants were colonized by 1 mo of age, compared with $60-90 \%$ in the 1980 s $(19,20,23,24)$ and $80 \%$ in the 1970s (25) in Sweden. E. coli thrives only in the intestines of man and animals and is spread by fecal contamination. In the 1970s, around a quarter of vaginally delivered infants acquired $E$. coli from their mothers; the rest were colonized by strains spread by the hospital staff (25). Today, short hospital stays, rooming-in, and better hospital hygiene might have reduced such exposure. Other enterobacteria that commonly colonize newborn infants, such as Klebsiella and Enterobacter spp., rarely derive from the mother but spread in maternity and neonatal wards $(3,6)$. Only $18 \%$ of the vaginally delivered infants examined here had such bacteria at $1 \mathrm{wk}$, which can be compared with $>40 \%$ in a previous study performed by us in the 1980s (8). This confirms the declining colonization of Swedish infants by hospital bacteria.

Enterococci are also typical fecal bacteria, but they are more resistant than others to hygienic measures (26). Enterococci were isolated by us as often as reported previously (20), 
and cesarean section-delivered infants were equally early colonized as those delivered vaginally. This shows that some bacteria resist hygiene better than others. Among these are clostridia, which form spores that resist disinfectants and occur in abundance in the environment (27). Hence, clostridia dominated the early anaerobic flora in cesarean sectiondelivered infants.

Bifidobacteria may be transferred from the mother during delivery (7) and they were more frequent in vaginally compared with cesarean section-delivered infants in the first week. However, the cesarean section-delivered infants soon acquired bifidobacteria from yet undefined sources. Bifidobacteria are relatively tolerant to ambient oxygen, which may facilitate their spread (3). As most infants were colonized by bifidobacteria, they seem not to have been reduced by the contemporary lifestyle.

Spread of fecal bacteria appears to have diminished not only in the modern hospital, but also in families. Thus, cesarean section-delivered infants had not yet caught up with vaginally delivered infants with respect to $E$. coli colonization by 6 mo of age. In earlier studies from Western countries, this process seems to have occurred faster $(28,29)$, and in Pakistan, practically all cesarean section-delivered infants acquire $E$. coli within a week (8).

Bacteroides were also isolated less often than in earlier Swedish studies $(5,20)$, and many cesarean section-delivered infants had not yet acquired Bacteroides by $1 \mathrm{y}$ of age. In a recent study from Finland (4), Bacteroides was delayed in cesarean section-delivered infants up to 6 mo of age and in studies from Western countries in the 1980s at least during the first weeks of life $(5,28)$. By contrast, in Nigeria, both vaginally and cesarean section-delivered infants harbor Bacteroides within a week in most cases (30). We regard the delayed Bacteroides colonization as another indication of limited circulation of fecal bacteria today.

As a more and more complex anaerobic flora develops the facultatives are suppressed (3). This was manifested by declining counts of enterobacteria and enterococci after $6 \mathrm{mo}$ of age. The counts of coagulase-negative staphylococci dropped faster and more strikingly, which was also observed for $S$. aureus (14). Their inability to compete with other bacteria in a microflora of increased complexity distinguish them from more "professional" intestinal bacteria. The presence of staphylococci in almost all 1-y-old infants indicates a slow acquisition of a highly complex microflora in Swedish infants today. Another sign of this is that $C$. difficile isolation rates increased steadily up to $12 \mathrm{mo}$ of age. C. difficile is common in the microflora of young infants, but firmly suppressed by the anaerobic flora in adults (27). In a Swedish study performed some $15 \mathrm{y}$ ago, colonization by $C$. difficile peaked at around 6 mo of age, where after it decreased (31).

Antibiotics influence intestinal colonization $(5,19)$ and a quarter of the infants examined here received antibiotics in their first year. However, because treated infants tended to have more E. coli and S. aureus, but less clostridia, antibiotic treatment could neither explain low colonization rates of $E$. coli and Bacteroides, nor the abundance of coagulase-negative staphylococci. S. aureus was also very prevalent in infants who had not received antibiotics (unpublished observations). Moreover, although antibiotic utilization increased steadily in Sweden until the mid-1990s, it decreased thereafter, especially in children. For instance, consumption of penicillin and macrolides in the age group 0-6y is similar today compared with 1974 (32). We do not regard antibiotic treatment of infants as a significant cause of delayed colonization by fecal bacteria.

Six mothers received antibiotics during or after delivery. Their infants acquired E. coli very late and tended to have less clostridia and bifidobacteria. As three of these infants were delivered by caesarean section, the contribution of maternal antibiotics is difficult to judge. However, these few infants could only minimally affect the colonization pattern of the cohort. Therefore, maternal antibiotics could also not explain the slow colonization by typical faecal bacteria.

The present study suggests that Gram-negative bacteria (enterobacteria and Bacteroides) seem to have decreased in the last decades, whereas Gram-positive bacteria (enterococci, bifidobacteria, clostridia and staphylococci) remain high or have even increased. As the intestinal microflora is a common source of bacteria causing extraintestinal infections, it is interesting to note that staphylococci are the most common cause of neonatal septicemia today (33). Furthermore, the intestinal microflora is the major drive for the gut immune system (10). Inasmuch as Gram-positive and Gram-negative bacteria induce partly different mediators when interacting with the innate immune system (34), a changed colonization pattern caused by increased hygiene may have global effects on the developing infantile immune system.

Acknowledgments. The authors thank Birgitta Åberg for excellent help in collection of samples and with interviews, and all the parents and infants for their contribution. We also thank Eva Ågren, Ingela Kinell, and Jolanta Bonislavska for their skillful technical assistance.

\section{REFERENCES}

1. Mata LJ, Urrutia JJ 1971 Intestinal colonization of breastfed children in a rural area of low socio-economic level. Ann N Y Acad Sci 176:93-109

2. Stark PL, Lee A 1982 The microbial ecology of the large bowel of breast-fed and formula-fed infants during the first year of life. J Med Microbiol 15:189-203

3. Adlerberth I, Hansson LA, Wold AE 1999 The ontogeny of the intestinal flora. In: Sanderson IR, Walker WA (eds) Development of the Gastrointestinal Tract. BC Decker, Hamilton, pp 279-292

4. Gronlund MM, Lehtonen OP, Eerola E, Kero P 1999 Fecal microflora in healthy infants born by different methods of delivery: permanent changes in intestinal flora after cesarean delivery. J Pediatr Gastroenterol Nutr 28:19-25

5. Bennet R, Nord CE 1987 Development of the faecal anaerobic microflora after caesarean section and treatment with antibiotics in newborn infants. Infection $15: 332-336$

6. Fryklund B, Tullus K, Berglund B, Burman LG 1992 Importance of the environment and the faecal flora of infants, nursing staff and parents as sources of gram-negative bacteria colonizing newborns in three neonatal wards. Infection 20:253-257

7. Tannock GW, Fuller R, Smith SL, Hall MA 1990 Plasmid profiling of members of the family Enterobacteriaceae, lactobacilli, and bifidobacteria to study the transmission of bacteria from mother to infant. J Clin Microbiol 28:1225-1228

8. Adlerberth I, Carlsson B, de Man P, Jalil F, Khan SR, Larsson P, Mellander L, Svanborg C, Wold AE, Hanson LÅ 1991 Intestinal colonization with Enterobacteriaceae in Pakistani and Swedish hospital-delivered infants. Acta Paediatr Scand 80:602-610

9. Bennet R, Eriksson M, Tafari N, Nord CE 1991 Intestinal bacteria of newborn Ethiopian infants in relation to antibiotic treatment and colonisation by potentially pathogenic Gram-negative bacteria. Scand J Infect Dis 23:63-69

10. Cebra JJ (1999) Influences of microbiota on intestinal immune system development Am J Clin Nutr 69:1046S-1051S 
11. Moreau MC, Corthier G 1988 Effect of the gastrointestinal microflora on induction and maintenance of oral tolerance to ovalbumin in $\mathrm{C} 3 \mathrm{H} / \mathrm{HeJ}$ mice. Infect Immun 56:2766-2768

12. Wold AE 1998 The hygiene hypothesis revised: is the rising frequency of allergy due to changes in the intestinal flora? Allergy 53:20-25

13. Nowrouzian F, Hesselmar B, Saalman R, Strannegard IL, Aberg N, Wold AE, Adlerberth I 2003 Escherichia coli in infants' intestinal microflora: colonization rate, strain turnover, and virulence gene carriage. Pediatr Res 2003;54:8-14

14. Lindberg E, Nowrouzian F, Adlerberth I, Wold AE 2000 Long-time persistence of superantigen-producing Staphylococcus aureus strains in the intestinal microflora of healthy infants. Pediatr Res 48:741-747

15. Ahrné S, Lönnermark E, Wold AE, Åberg N, Hesselmar B, Saalman R, Strannegard IL, Molin G, Alderberth I 2005 Lactobacilli in the intestinal microbiota of Swedish infants. Microbes Infect 7:1256-1262

16. Roy D, Sirois S 2000 Molecular differentiation of Bifidobacterium species with amplified ribosomal DNA restriction analysis and alignment of short regions of the ldh gene. FEMS Microbiol Lett 191:17-24

17. Bullen CL, Tearle PV, Willis AT 1976 Bifidobacteria in the intestinal tract of infants: an in vivo study. J Med Microbiol 9:325-333

18. McAllister TA, Givan J, Black A, Turner MJ, Kerr MM, Hutchison JH 1974 The natural history of bacterial colonization of the newborn in a maternity hospital. I. Scott Med J 19:119-124

19. Bennet R, Eriksson M, Nord CE, Zetterstrom R 1986 Fecal bacterial microflora of newborn infants during intensive care management and treatment with five antibiotic regimens. Pediatr Infect Dis 5:533-539

20. Lundequist B, Nord CE, Winberg J 1985 The composition of the faecal microflora in breastfed and bottle fed infants from birth to eight weeks. Acta Paediatr Scand $74: 45-51$

21. Borderon JC, Lionnet C, Rondeau C, Suc Al, Laugier J, Gold F 1996 Current aspects of fecal flora of the newborn without antibiotherapy during the first 7 days of life: Enterobacteriaceae, enterococci, staphylococci. Pathol Biol 44:416-422

22. Balmer SE, Wharton BA 1989 Diet and faecal flora in the newborn: breast milk and infant formula. Arch Dis Child 64:1672-1677

23. Kuhn I, Tullus K, Möllby R 1986 Colonization and persistence of Escherichia coli phenotypes in the intestines of children aged 0 to 18 months. Infection 14:7-12

24. Tullus K, Kallenius G, Mollby R 1988 Faecal colonization with P-fimbriated Escherichia coli between 0 and 18 months of age. Epidemiol Infect 100:185-191
25. Gothefors L, Carlsson B, Ahlstedt S, Hanson LA, Winberg J 1976 Influence of maternal gut flora and colostral and cord serum antibodies on presence of Escherichia coli in faeces of the newborn infant. Acta Paediatr Scand 65:225-232

26. Kearns AM, Freeman R, Lightfoot NF 1995 Nosocomial enterococci: resistance to heat and sodium hypochlorite. J Hosp Infect 30:193-199

27. Wilson KH 1993 The microecology of Clostridium difficile. Clin Infect Dis 16(suppl 4):S214-S218

28. Balmer SE, Scott PH, Wharton BA 1989 Diet and faecal flora in the newborn: lactoferrin. Arch Dis Child 64:1685-1690

29. Lennox-King SM, O'Farrell SM, Bettelheim KA, Shooter RA 1976 Colonization of caesarean section babies by Escherichia coli. Infection 4:134-138

30. Rotimi VO, Olowe SA, Ahmed I 1985 The development of bacterial flora of premature neonates. J Hyg (Lond) 94:309-318

31. Tullus K, Aronsson B, Marcus S, Mollby R 1989 Intestinal colonization with Clostridium difficile in infants up to 18 months of age. Eur J Clin Microbiol Infect Dis 8:390-393

32. Swedish Strategic Programme for the Rational Use of Antimicrobial Agents and Surveillance of Resistance. Available at: www.strama.org

33. Kallman J, Kihlstrom E, Sjoberg L, Schollin J 1997 Increase of staphylococci in neonatal septicaemia: a fourteen-year study. Acta Paediatr 86:533-538

34. Hessle C, Andersson B, Wold AE 2000 Gram-positive bacteria are potent inducers of monocytic interleukin-12 (IL-12) while Gram-negative bacteria preferentially stimulate IL-10 production. Infect Immun 68:3581-3586

35. Kauffman F 1969 The Bacteriology of Enterobacteriaceae. 2nd Ed. Munkgaard, Copenhagen, pp 362-363

36. Chapman GH 1949 Comparison of Ludlam's medium with Staphylococcus medium number 110 for the isolation of staphylococci that clot blood. J Bacteriol 58:823

37. Isenberg HD, Goldberg D, Sampson J 1970 Laboratory studies with a selective Enterococcus medium. Appl Microbiol 20:433-436

38. Livingston SJ, Kominos SD, Yee RB 1978 New medium for selection and presumptive identification of the Bacteroides fragilis group. J Clin Microbiol 7:448-453

39. Beerens H 1991 Detection of bifidobacteria by using propionic acid as a selective agent. Appl Environ Microbiol 57:2418-2419

40. George WL, Sutter VL, Citron D, Finegold SM 1979 Selective and differential medium for isolation of Clostridium difficile. J Clin Microbiol 9:214-219 